\title{
SUSTENTABILIDADE NO TRABALHO E GOVERNANÇA CORPORATIVA, COMO PODEMOS TER A JUNÇÃO DE AMBOS?
}

\section{SUSTAINABILITY AT WORK AND CORPORATE GOVERNANCE, HOW CAN WE JOIN BOTH?}

\author{
Gleibe Pretti ${ }^{1}$, Elias Marques de Medeiros Neto ${ }^{2}$
}

Submetido em: 04/09/2021

Aprovado: 14/09/2021

\section{RESUMO}

No presente trabalho, foi realizada a análise acerca da sustentabilidade nas empresas, sua aplicação prática e a governança corporativa, ambas devem caminhar unidas. O novo ambiente laboral, com o intuito de atender às necessidades não apenas dos empregados, mas dos produtos e serviços que essa empresa comercializa, são fontes e subsídios que podem fazer a diferença para a valorização do trabalho humano. O objetivo geral desse trabalho foi justamente ter uma concepção da sustentabilidade e da governança e de forma específica, como ambas podem se relacionar. Para tanto, foi realizada uma pesquisa qualitativa, exploratória e bibliográfica. Verificou-se que o meio ambiente laboral sustentável está diretamente relacionado com a qualidade de vida dos trabalhadores. Por intermédio de uma gestão organizacional sustentável há a concretização do valor jurídico e social da dignidade do ser humano, com reflexos diretos no progresso da sociedade e no alcance do objetivo maior do desenvolvimento sustentável.

PALAVRAS-CHAVE: Sustentabilidade. Meio ambiente de trabalho. Desenvolvimento Sustentável. Dimensão social. Organizações. Governança corporativa. Teletrabalho.

\section{ABSTRACT}

The analysis about sustainability in companies, its practical application and corporate governance, must go hand in

${ }^{1}$ Doutorando pela UNIMAR. Mestrado Concluído pela- UnG-Univeritas (2017). Pós-graduado em Direito Constitucional pela UNIFIA- UNISEPE. (2015). Pós-graduado em Direito e Processo do Trabalho pela UNIFIA- UNISEPE (2015). Graduado, em Direito, pela Universidade São Francisco (2002). Sociólogo pela Faculdade Paulista São José. (2016). Pós-graduando em educação e novas metodologias de ensino EAD, pela Estácio, Graduando em história- Faculdade Sumaré. Jornalista inscrito no Ministério do Trabalho. Formação em educação em neurociência (neuroaprendizagem e cognição). Curso de LIBRAS, USP- 20 HS, Advogado, Professor do Centro Universitário Estácio- graduação e pósgraduação. Coordenador da pós-graduação, lato sensu, do Centro Universitário Estácio de Sá (SP), Professor da graduação, em direito, na Unidrummond. Professor da graduação, em direito, na Piaget. Professor do curso estratégia, Professor da pós-graduação da Editora conceito, Conteudista da Telesapiens, LFG- Kroton- Saraiva, FAM, Laureate- FMU, Elaborador do projeto pedagógico- YDUQS- Estácio- Nova matriz curricular; Avaliador do MEC, tanto para autorização como renovação de cursos de direito. Avaliador do INEP.

${ }^{2}$ Pós-doutorado em Direito Processual Civil na Faculdade de Direito da Universidade de Lisboa (2015). Pós-doutorado em Democracia e Direitos Humanos, com foco em Direito Processual Civil, na Faculdade de Direito da Universidade de Coimbra/lus Gentium Conimbrigae (2019). Pós-doutorado em Direitos Sociais, com foco em Direito Processual Civil, na Faculdade de Direito da Universidade de Salamanca (2019/2021). Doutor e Mestre em Direito Processual Civil pela PUC/SP. MBA em Gestão Empresarial pela FGV (2012). Especialista em Direito da Economia e da Empresa pela FGV (2006). Especializações em Direito Processual Civil (2004) e em Direito dos Contratos (2005) pelo IICS/CEU. Pósgraduação Executiva no Programa de Negociação da Harvard Law School (2013). Pós-graduação Executiva no Programa de Mediação da Harvard Law School (2015). Pós-graduação Executiva em Business \& Compliance na University of Central Florida - UCF (2017). Pós-graduação Executiva em Mediação e Arbitragem Comercial Internacional pela American University / Washington College of Law (2018). Pós-graduação Executiva em U.S. Legal Practice and ADR pela Pepperdine University/Straus Institute for Dispute Resolution (2020). 


\section{revista educação}

SUSTENTABILIDADE NO TRABALHO E GOVERNANÇA CORPORATIVA COMO PODEMOS TER A JUNÇÃO DE AMBOS? Gleibe Pretti, Elias Marques de Medeiros Neto

hand. The new work environment, in order to meet the needs not only of employees, but of the products and services that this company sells, are sources and subsidies that can make a difference for the valorization of human work. The general objective of this work is precisely to have a conception of sustainability and governance and in a specific way, as both can be related. For this, a qualitative, exploratory and bibliographic research was carried out. It was found that the sustainable working environment is directly related to the quality of life of workers. Through sustainable organizational management, there is the realization of the legal and social value of human dignity, with direct consequences for the progress of society and the achievement of the major objective of sustainable development.

KEYWORDS: Sustainability. Working environment. Sustainable development. Social dimension. Organizations. Corporate governance. Teleworking. 


\section{INTRODUÇÃO}

Os aspectos inovadores da sustentabilidade, assim como, sua visão e interpretação mais ampla de aplicação não apenas no meio ambiente, traz uma nova perspectiva de aplicação dos conceitos do tema e sua junção com a governança corporativa traz em seus pormenores, uma inovação aos envolvidos.

Realizou-se pesquisa exploratória, prezando pelo levantamento bibliográfico, sobretudo de obras de renomados autores do campo jurídico clássico e de autores cujas obras dedicam-se a explanar os conceitos abordados pelos clássicos.

Com base nos procedimentos técnicos utilizados, que têm como objetivo confrontar a visão teórica com os dados da realidade, é importante ressaltar o delineamento da pesquisa. Nesse ponto o delineamento refere-se ao planejamento da pesquisa em sua dimensão mais ampla, que envolve tanto a diagramação quanto a previsão de análise e interpretação de coleta de dados. Entre outros aspectos, o delineamento considera o ambiente em que são coletados os dados e as formas de controle das variáveis envolvidas.

Como ponto de vista, cabe também observar os atos praticados nos tribunais, principalmente no que se refere à sustentabilidade e governança.

Levando-se em consideração os aspectos teórico-exploratórios da pesquisa e sua relevância na atualidade, o foco do trabalho será descrever as características do tema em tela.

\section{A CONCRETIZAÇÃO DOS DIREITOS SOCIAIS E O NOVO PAPEL DAS ORGANIZAÇÕES}

O objetivo das corporações, atualmente, é justamente encontrar uma equação e equilíbrio entre a lucratividade e o respeito aos direitos sociais. Correto afirmar que, com as redes sociais e a divulgação das informações, as empresas, através de gestores responsáveis, estão encontrando soluções que sejam favoráveis a todos os lados.

Continuando na mesma linha, pois a atual visão não é apenas de reconhecer os direitos sociais, mas de protegê-los, vivenciá-los e concretizá-los. Dessa forma:

[...] não se trata de saber quais e quantos são esses direitos, qual é sua natureza e seu fundamento, se são direitos naturais ou históricos, absolutos ou relativos, mas sim qual é o modo mais seguro para garanti-lo, para impedir que, apesar das solenes declarações, eles sejam continuamente violados (BOBBIO, 1992, p. 25).

Essas alterações na gestão das empresas se coadunam com a opção do constituinte brasileiro que assegura na propriedade uma dúplice finalidade: individual e social.

Para que se possa entender, por função individual tem-se que a propriedade é um direito da pessoa, com o fim de servir ao proprietário e sua prole.

Por função social entende-se a verificação da propriedade ao bem comum, ou seja, denotam-se os deveres que a propriedade privada tem para com os demais membros da sociedade, sendo que desses deveres derivam suas metas: "A propriedade não é um direito absoluto e ilimitado, como o concebeu a filosofia liberal, mas um direito limitado pelos deveres sociais" (NALINI, 2003, p. 170). Hans Küng (1999, p. 397) destaca que a propriedade, independentemente do tamanho, acarreta obrigações: "O uso da propriedade também deve servir ao bem de todos. Só assim poderá ser edificada uma ordem econômica justa".

Desta forma, como atender aos interesses que são díspares, quando abordamos o individual e o coletivo? A resposta é aquela que atenda ao bem comum, situação essa que deverá ser analisada do ponto de vista mais profundo. 


\section{SUSTENTABILIDADE, DESENVOLVIMENTO SUSTENTÁVEL, RESPONSABILIDADE SOCIAL E FUNÇÃO SO- CIAL}

Tecendo algumas lições, na ecologia, a palavra sustentabilidade descreve como os sistemas biológicos se mantêm uma série de diferenças e produtivos ao longo do tempo (JACOBI; RAUFFLET; ARRUDA; 2011, p. 23). Com o agravamento dos problemas ambientais e sociais, o termo passou a ser aplicado em diversas áreas do saber e o conceito agregou, além do critério ambiental, questões econômicas sociais e culturais.

Destarte, para os indivíduos, a sustentabilidade é o que potencializa de manutenção de bem-estar por um longo período, o que possui dimensões ambientais, econômicas e sociais (JACOBI; RAUFFLET; ARRUDA; 2011, p. 23).

Abordando, nesse ínterim, a responsabilidade social, é necessário um cuidado para não a confundir com a função social ou obrigação social imposta pela legislação às empresas. Consoante expõe Felix (2003, p. 19):

Ser socialmente responsável não significa respeitar e cumprir devidamente as obrigações legais, mas sim, o fato de empresas irem além de suas obrigações em relação ao seu capital humano, ao meio ambiente e à comunidade por perceberem que o bem-estar deles reflete em seu bem-estar.

Nesse passo, as lições de Archie Carrol (Apud LOURENÇO; SCHRÖDER, 2003, p. 87-88) subdividiu a responsabilidade social da empresa em quatro tipos: econômico, os quais iremos transcrever, sendo eles: legal, ético e discricionário ou filantrópico. A primeira delas, a responsabilidade econômica, é o principal tipo de responsabilidade encontrada nas empresas, na qual o lucro é a maior razão para sua existência.

O doutrinador citado acima, ainda continua afirmando que ter responsabilidade econômica significa produzir bens e serviços de que a sociedade necessita e quer, a um preço, que se garanta a continuação das atividades da empresa. No patamar da responsabilidade legal, as empresas buscam as metas econômicas dentro da estrutura e exigências legais. Já no plano da responsabilidade ética, a empresa inclui em suas atividades comportamentos que a sociedade espera que ela adote, mesmo que não haja previsão legal e que não atenda aos interesses econômicos diretos da empresa. Por fim, a responsabilidade discricionária ou filantrópica é puramente voluntária e orientada pelo desejo da empresa em fazer uma contribuição social não imposta pela economia, pela lei ou pela ética.

Como pode-se verificar, a mudança de pensamento e de paradigmas é o escopo das novas empresas responsáveis com a sociedade. Verificamos essa situação, na prática, em empresas que pretendem sobreviver no mercado, com uma gestão focada nesse aspecto.

\section{AS DIMENSÕES DA SUSTENTABILIDADE}

Na visão global, foi desenvolvida a tese descrita por Maia e Pires (2011, p. 182), que destacam que o desenvolvimento sustentável significa prosperidade de uma forma geral e global compartilhada e ambientalmente sustentável.

Indicam que, para o desenvolvimento sustentável, são necessárias três mudanças fundamentais: sustentabilidade ambiental, estabilização populacional e fim da miséria. Essas mudanças só poderão ser alcançadas com uma mobilização global, fundamentada em um processo de cooperação e interação entre povos, mas que exigirá negociação e acomodação entre as visões de mundo criadas pelas pessoas, regiões e nações sobre a sustentabilidade.

Conforme a lição acima, é necessário que sejam realizados atos para que possa mudar a cultura, como de início a educação, não apenas nas escolas, mas atos constantes nas empresas, desta forma, o crescimento será muito maior e salutar a todos os envolvidos.

\section{O MEIO AMBIENTE DE TRABALHO}

Antes de iniciar esse ponto, alguns conceitos se fazem necessários, como a abordagem da questão ambiental 
deve englobar seus aspectos artificiais, sociais, culturais, econômicos e políticos, buscando como ligação, que todos esses fatores contribuem para a sua formação e alteração.

Destarte, José Afonso (2004, p. 20) considera meio ambiente toda a natureza original e artificial, bem como os bens culturais correlatos, compreendendo-se não apenas a água, o solo, o ar, mas também o patrimônio histórico, turístico, arqueológicos entre outros.

Essa concepção é ampla, pois abrange tudo aquilo que permite a vida, que a abriga e rege.

Nessa mesma vertente, dentre os vários aspectos que formam o meio ambiente, o denominado meio ambiente de trabalho constitui o local onde as pessoas desempenham seu trabalho, de forma remunerada ou não, cujo equilíbrio está baseado tanto na salubridade do meio como na ausência de agentes que comprometam a incolumidade físico-psíquica dos trabalhadores, independente da condição que ostentem, o que é muito salutar (homem, mulher, jovem, servidos público, autônomos) (FIORILLO, 2004, p. 23).

Nas lições de Diniz e Maciel (2012, p. 500), o meio ambiente de trabalho pode assumir os seguintes aspectos: a) fisiológico, que corresponde ao grau de adaptação do trabalhador ao meio físico; b) moral, decorrente de aptidões humanas, motivação, grau de satisfação, personalidade etc. c) social, ou seja, a interdependência entre o trabalho e a sociedade; d) econômico, relacionado com a produção de riquezas, propriedade, os bens produzidos, organizações empresariais e outros.

Diante do arrazoado, verifica-se que o conceito de meio ambiente do trabalho é muito mais amplo do que apenas às questões puramente ambientais.

\section{A SUSTENTABILIDADE NO MEIO AMBIENTE DE TRABALHO}

A base inicial para o estudo é justamente a Constituição Federal Brasileira, que estabeleceu, no seu art. $1^{\circ}$, IV, como um dos fundamentos do Estado Democrático de Direito, a proteção dos valores sociais do trabalho, como expressão básica da proteção à personalidade humana e como forma de buscar o equilíbrio social e econômico.

Como base jurídica, outrossim, o artigo 170 da Constituição da República preconiza a humanização que deve existir no ambiente de trabalho, ao fixar que a ordem econômica tem por fim assegurar a todos uma vida digna, conforme os ditames da justiça social, fundada na valorização do trabalho humano e na livre iniciativa. Acrescente-se que o art. 193 da Constituição Federal estabelece que a ordem social tem por base o trabalho, com o intuito o bem-estar e a justiça social.

O parâmetro trazido por Minardi (2010, p. 76), a competitividade do atual sistema capitalista, renovado pela globalização e por uma situação em que resgata o liberalismo econômico, tem exigido dos trabalhadores um esforço para o aumento da produtividade, aliado à cobrança de aperfeiçoamento e resultados, acarretando euforia, ansiedade, irritação, angústia e outros problemas de saúde ao trabalhador.

Há uma busca na doutrina pela lição em que a concretização do desenvolvimento sustentável pressupõe, necessariamente, o atendimento das mais elementares necessidades da população, articulando a defesa da melhoria da saúde, condições ambientais e socioeconômicas. O paralelo entre a saúde com o meio ambiente refere-se não somente à preservação do meio ambiente geral, mas também dos locais de trabalho. Para o desenvolvimento sustentável não é possível promover a saúde e o bem-estar sem desenvolvimento econômico e social, ambos devem estar juntos. (MACHADO, 2001, p. 71).

Tendo como parâmetro, nesse sentido, Tamiozzo (2012, p. 406) assevera que as organizações começam a desenvolver ações sociais com o objetivo de melhorar a qualidade de vida no labor e obter ganhos de produtividade com uma equipe motivada, e interessada no crescimento de todos com o alcance dos resultados almejados, o que faz surgir uma nova cultura na empresa, centrada na valorização das ações sociais externas e na prática do voluntariado.

A empresa quando realiza ações organizacionais para que o trabalhador se sinta participante de um processo, a atividade por ele cumprida proporciona uma consciência mais ampla de si mesmo e do seu trabalho, fomentando a cidadania e o equilíbrio social. Nesse contexto, Diniz e Maciel (2012, p. 501) ressaltam que: 
[...] o trabalho passa a ser um elemento ativo, cria uma condição para que o homem se exponha de forma criativa, que se traduz na apresentação das suas potencialidades, gerando novas capacidades, colocando-o no seu verdadeiro posto, que é ser sujeito de ações.

Uma atividade econômica responsável consiste em unir estratégias econômicas com o julgamento ético. Este novo paradigma de ethos econômico passa a ser concreto quando, não obstante o interesse pelo lucro, analisa-se o agir econômico para ver se não ofende bens e valores mais elevados, se é social e ecologicamente aceitável (KÜNG, 1999, p. 405 e 408).

\section{OS DESAFIOS PARA O IMPLEMENTO DA SUSTENTABILIDADE NO MEIO AMBIENTE LABORAL - NOVA VI- SÃO CORPORATIVA}

Com o escopo e encontrar formas práticas para aplicação da sustentabilidade, nessa linha, Vinha (2003), a partir da corrente da economia ecológica, aponta que mudanças ocorreram e os recursos naturais deixaram de ser percebidos como uma externalidade negativa e muitos acadêmicos passaram a analisar a sustentabilidade como um diferencial competitivo nas organizações.

As empresas começaram a alterar os seus processos e a implantar o conceito de qualidade total nas organizações. Com essas mudanças, as organizações perceberam os ganhos de produtividade e a redução de custos financeiros. Essas alterações e a implantação de ações sustentáveis foram pioneiras nas grandes corporações, motivadas pelas cobranças sociais e pelas intervenções políticas (VINHA, 2003).

Evidentemente que as empresas estão encontrando formas e novos meios de se adaptarem a essa nova realidade.

Adentra nesse aspecto, Coral (2002) afirma que o desafio para obter o equilíbrio do tripé da sustentabilidade necessita de intervenções em todos os níveis da economia. No nível macro, são elaboradas as diretrizes para as políticas internacionais e nacionais a fim de estabelecer parcerias e priorizar ações. A partir das discussões, conferências e protocolos assinados por diversos países, de forma voluntária ou legalmente estabelecidos, são crescentes o acompanhamento e cobranças dos órgãos internacionais como a Organizações das Nações Unidas (ONU) sobre as empresas no cumprimento de princípios e diretrizes de responsabilidade social a serem seguidos (Compêndio para a Sustentabilidade, 2007).

$\mathrm{Na}$ origem, o termo governança corporativa vem da expressão inglesa Corporate Governance. Apesar de existir há mais de meia década, nos últimos anos diversos países estão percebendo a necessidade deste tema e estão se preocupando mais com as empresas.

Sobre esse tema, tem-se diversas lições vinculadas às temáticas da responsabilidade social corporativa e da sustentabilidade. Na visão de Bowen (1957), a responsabilidade social nas empresas deixaria de ser apenas um conjunto de ações paternalistas de filantropia para estar inserida nas políticas no conglomerado das empresas. (MILANI et al., 2012).

Nessa mesma linha, em suas palavras, Silva (2005, p. 11) diz que: "embora a governança corporativa não seja um tema relativamente novo, somente nos últimos anos vem se transformando em uma preocupação importante em diversos países, sejam mercados desenvolvidos ou emergentes".

Nessa esteira, Sena (2007, p. 25): "A governança corporativa é um conjunto de práticas que tem por finalidade otimizar o desempenho de uma companhia, protegendo investidores, empregados e credores, facilitando, assim, o acesso ao capital".

Para Leal (2002, p. 09), governança corporativa seria:

O sistema de governança corporativa é o conjunto de práticas e processos formais de supervisão da gestão executiva de uma empresa que visa resguardar os interesses dos acionistas e minimizar os conflitos de interesse entre os acionistas e os demais afetados pelo valor da empresa. 
Pode-se afirmar que nos últimos anos a Governança vem crescendo muito no Brasil. No Brasil, o debate em torno da governança corporativa se intensificou bastante da última década, na medida em que as relações entre acionistas e administradores e entre acionistas majoritários e minoritários buscam uma mudança com a reestruturação societária provocada pelas privatizações e a entrada de novos sócios nas empresas do setor privado, principalmente estrangeiros. Temos que o Estado-empresário no Brasil tinha algumas características do modelo stakeholder, que foram sendo redefinidas com a privatização de alguns segmentos e a adoção de um foco maior na rentabilidade para atrair investimentos para privatizações. (SILVA, 2005. p. 21)

A governança corporativa pode ser considerada como um ambiente de confiança, ética, valores morais - como um esforço sinérgico de todos os componentes da sociedade - isto é, os stakeholders, incluindo o governo, os profissionais, os prestadores de serviços e o setor da empresa e tudo isso pode ser reforçado com um novo paradigma de governança corporativa que está em sintonia com a mudança dos tempos e que considera a demanda por uma maior responsabilidade nas empresas (BUSHMAN; SMITH, 2001).

Como uma lição e parâmetro, Michelon e Parbonetti (2012) discorrem que a divulgação das ações em prol da sustentabilidade pode ser percebida como mecanismos complementares de legitimidade e que as empresas devem aplicar para a construção de diálogos com os stakeholderes. A legitimidade organizacional, além de garantir o fluxo de capital, trabalho e clientes necessários para a viabilidade da empresa (PFEFFER; SALANCIK 2003; NEU et al.,1998), também é capaz de reduzir possíveis boicotes de produtos e ações de ruptura causados por abalos na reputação, sempre pelo aspecto ético, que o mercado exige atualmente. (ELSBACH, 1994).

O desenvolvimento sustentável foi popularizado pelo Relatório Brundtland como "[...] the development that meets the needs of the present without compromising the ability of future generations to meet their own needs" (WCED, 1987, p. 56). Tendo como base uma visão otimista, entre economia e ambiente, a ênfase colocada na relação futura entre 'necessidades' e 'limites', sem apresentar um qualquer sistema de prioridades, tornou a subsequente interpretação do conceito ambígua e pouco precisa (REDCLIFT, 1993; WILBANKS, 1995; DRYSEK, 1997).

Para não tergiversar e ir direto ao ponto, o período que se vive, de constantes debates sobre a necessidade da sustentabilidade, cria um terreno fértil não só para a ampliação e aprofundamento das pesquisas no campo acadêmico, mas principalmente para as organizações compreenderem e intentarem ações em direção à lógica do desenvolvimento sustentável. Se faz mister, então, compreender que os esforços aplicados no processo do desenvolvimento sustentável podem conduzir para a sustentabilidade, tanto como produto final quanto na geração de qualidade no processo (DREHER; CASAGRANDE, 2012).

Aprofundando o tema, quanto a isso, Elkington (1999) observa que o momento atual de revolução cultural exige que as corporações estejam preparadas para se dirigirem na direção de uma forma sustentável. Manzini e Vezzoli (2002) afirmam que a humanidade está passando por um período de descontinuidade sistêmica, caracterizada pela tensão entre a globalização econômica, cultural, e a emergência dos limites ambientais, exigindo a transição para uma sociedade com o intuito de ser sustentável.

Na doutrina encontra-se as palavras de Savitz e Weber (2006). Para os autores, existem três maneiras de a sustentabilidade melhorar a empresa, ajudando a protegê-la, a gerenciá-la, e a promover sua ascensão. A sustentabilidade é como um guia de orientação para as negociatas num mundo interdependente, indicando novas maneiras de proteger a empresa contra riscos ambientais, financeiros e sociais, de dirigir a empresa com maior eficiência e produtividade, e de promover seu crescimento por meio do desenvolvimento de novos produtos e serviços e da abertura de novos mercados.

Do ponto de vista prático, Savitz e Weber (2006) destacam que o aquecimento global está alterando o panorama comercial e regulatório das empresas, e elas estão reagindo a esses desafios. Por exemplo, a Toyota desenvolveu um motor híbrido gasolina-electricidade. A DuPont se afasta de produtos químicos para se transformar no maior produtor mundial de proteína de soja. A PepsiCo relata aumento anual de US\$250 milhões na receita de vendas, por aplicar em programas que dão preferência a fornecedores sob controle societário de mulheres e grupos minoritários. A 3M reporta economias superiores a US\$ 1 bilhão com seu programa Pollution Prevention Pays (Vale a pena evitar a poluição). Para os doutrinadores em tela, também, a questão das mudanças climáticas representa 
grandes oportunidades de negócios, e já existem empresas colhendo o fruto do ponto doce da sustentabilidade. Para a General Electric (GE), o negócio de energia eólica já quadruplicou sua receita desde que foi adquirido da Enron, em 2002. Seus motores para aeronaves e locomotivas, com maior eficiência energética, e suas turbinas a gás natural, menos poluidoras, tornam-se cada vez mais essenciais para os interessados, que buscam maneiras de reduzir suas emissões de gases de efeito estufa. GE vendeu mais de US\$1 bilhão em turbinas a vento e a gás natural para China (SAVITZ; WEBER, 2006).

Assim, entende-se que a governança corporativa, nada mais é, em breves palavras, do que a junção de uma visão de responsabilidade social alinhada com as políticas da empresa; com cada empresa se adaptando ao seu estilo, sua cultura, assim como sua localização, não apenas no Brasil, mas no Mundo.

\section{CONCLUSÃO}

A individualidade, mesmo no sistema capitalista, está com seus dias marcados. A consciência do todo, mesmo nas relações empresariais, visa dar uma nova meta e parâmetro para todos os envolvidos. Logo, estamos diante de uma mudança de paradigma.

A alteração do paradigma, tem em seu escopo, evidentemente, não deixar de existir o lucro, mas com uma responsabilidade, especialmente de caráter social.

Tem-se que após uma grande pesquisa na área, o foco é implementar meios adequados para cada situação, assim como o respeito e características de cada empresa, e com o escopo de atender as regras exigidas por esse novo mercado, sobre sustentabilidade e governança. Com o mercado cada vez mais competitivo, essa nova visão das empresas será o segredo para a sua sobrevivência.

\section{REFERÊNCIAS}

BOBBIO, Norberto. A Era dos Direitos. 19. ed. Rio de Janeiro: Elsevier, 1992.

BONAVIDES, Paulo. Curso de Direito Constitucional. 13. ed. São Paulo: Malheiros, 2003

BOWEN, H. R. Responsabilidades sociais do homem de negócios. São Paulo. Editora Civilização Brasileira, 1957.

BUSHMAN, R. M., SMITH, A. J. Financial accounting information and corporate governance. Journal of accounting and Economics, v.32, p. 1, p. 237-333. 2001.

CORAL, E. Modelo de planejamento estratégico para a sustentabilidade empresarial. 05 de novembro de 2002. 275f. Tese (Doutorado em Engenharia de Produção) - Universidade Federal de Santa Catarina, Santa Catarina. 2002.

DERANI, Cristiane. Direito Ambiental Econômico. São Paulo: Max Limonad, 2001.

DINIZ, Bismarck Duarte; MACIEL, Joelson de Campos. O ambiente de trabalho e o princípio do desenvolvimento sustentável como limitações do poder econômico. In SILVA, Wanise Cabral;

MISAILIDIS, Mirta Gladys Lerena Manzo de; BARBATO, Maria Rosaria (org.). Anais do XXI Congresso Nacional do CONPEDI: O Novo Constitucionalismo Latino Americano: desafios da sustentabilidade. 978-85-7840-125-2. Florianópolis: FUNJAB, 2012. 
ELKINGTON, J. Cannibals with forks: the triple bottom line of 21st century business. Oxford: Capstone. 1997.

ELSBACH, K. D. Managing organizational legitimacy in the California cattle industry: The construction and effectiveness of verbal accounts. Administrative science quarterly, 1994.

ENGELS, Friedrich. Do Socialismo Utópico ao Socialismo Científico. Bauru: Edipro, 2010.

FELIX, Luiz Fernando Fortes. O ciclo virtuoso do desenvolvimento responsável. In BROCANELLI, Noelma (Org.). Responsabilidade Social das Empresas: a contribuição das universidades. v. II. São Paulo: Peirópolis, Instituto Ethos, 2003.

FIORILLO, Celso Antônio Pacheco. Curso de Direito Ambiental. 5. ed. São Paulo: Saraiva, 2004.

GIL, Antonio Carlos. Como elaborar projetos de pesquisa. 5. ed. São Paulo: Atlas, 2010.

GRAU, Eros Roberto. A Ordem Econômica na Constituição de 1998. 9. ed. São Paulo: Malheiros, 2004.

HANSON, Donald W. From Kingdom to Commonwealth. The Development of Civic Consciousness in English Political Thought. Cambridge, Mass.: Harvard University Press, 1970.

JACOBI, Pedro Roberto; RAUFFLET, Emmanuel; ARRUDA, Michelle Padovese. Educação para a Sustentabilidade nos Cursos de Administração: reflexão sobre paradigmas e práticas. In: RAM - Revista de Administração da Mackenzie. v. 12. n 3. Edição Especial. ISSN 1678- 6971. São Paulo: MAIO/JUN 2011.

KÜNG, HANS. Uma ética global para a política e economia mundiais. Rio de Janeiro: Vozes, 1999.

LEAL, Ricardo Pereira Camara; Ferreira, Vicente Antônio de Castro; Silva, André Luiz Carvalhal da. Governança Corporativa no Brasil e no Mundo. Rio de Janeiro; EPapers Serviços Editoriais Ltda., 2002.

LOURENÇO, Alex Guimarães e SCHRÖDER, Deborah de Souza. Vale investir em responsabilidade social empresarial? Stakeholders, ganhos e perdas. In: BROCANELLI, Noelma (Org.). Responsabilidade Social das Empresas: a contribuição das universidades. v. II. São Paulo: Peirópolis, Instituto Ethos, 2003.

MACHADO, Sidnei. O direito à proteção ao meio ambiente de trabalho no Brasil: os desafios para a construção de uma racionalidade normativa. São Paulo: LTr, 2001.

MAIA, Andrei Giovani; PIRES, Paulo dos Santos. Uma compreensão da sustentabilidade por meio dos níveis de complexidade das decisões organizacionais. In: RAM - Revista de Administração da Mackenzie. v. 12. n 3. Edição Especial. ISSN 1678-6971. São Paulo: MAIO/JUN 2011.

MANZINI, E.; VEZZOLI, C. O desenvolvimento de produtos sustentáveis. São Paulo: Editora da Universidade, 2002.

MARQUES NETO, Floriano Peixoto de Azevedo. Regulação Estatal e Interesses Públicos. São Paulo: Malheiros, 2002.

MICHELON, G., PARBONETTI, A. The effect of corporate governance on sustainability disclosure. Journal of Ma- 
nagement \& Governance, 16(3), 477-509. 2012.

MILANI, B., RIGHI, M. B.; CERETTA, P. S.; DIAS, V. Práticas de Sustentabilidade, Governança Corporativa e Responsabilidade Social afetam o risco e o retorno dos investimentos?. Revista de Administração da UFSM, v. 5, p. 667-682. 2012.

MINARDI, Fabio Freitas. Meio ambíente do trabalho: proteção jurídica à saúde mental. Curitiba: Juruá, 2010.

NALINI, José Renato. Ética Ambiental. 2. ed. São Paulo: Millennium, 2003.

NEU, D., WARSAME, H., PEDWELL, K. Managing public impressions: environmental disclosures in annual reports. Accounting, Organizations and Society, v. 23, n. 3, p. 265-282. 1998.

ONU - Organização das Nações Unidas. A ONU e o meio ambiente. Disponível em: http://www.onu.org.br/a-onu-em-acao/a-onu-e-o-meio-ambiente/. Acesso em: 31 mar. 21

PFEFFER, J.; SALANCIK, G. R. The external control of organizations: A resource dependence perspective. Stanford University Press, 2003.

PORTER, M.; LINDE, C. V. Green and Competitive: Ending the Stalemate. Harvard Business Review. p. 120-134, sep/oct, 1995.

REDCLIFT, Michael. Environmental Economics, Policy Consensus and Political Empowerment. In K. Turner (Org.). Sustainable Environmental Economics and Managements, pp. 106-119, London, Belhavem Press.

SAVITZ, A. W.; WEBER, K. The triple bottom line: how today's best-run companies are achieving economic, social, and environmental success - and how you can too. San Francisco: Wiley \& Sons, 2006.

SENA, Denilson Cesar; Governança Corporativa: estudo comparativo do desempenho econômico e financeiro das empresas nacionais integrantes do mercado de ações (BOVESPA). Universidade Positivo - Dissertação do Mestrado de Administração, Curitiba, 2007. Disponível em: http://www.up.com.br. Acesso em: 30 mar. 2021.

SILVA, André Luiz Carvalhal da. Governança Corporativa e Decisões Financeiras no Brasil. 2. ed. Rio de Janeiro: Mauad Editora Ltda., 2005.

SILVA, José Afonso da. Direito Ambiental Constitucional. 5. ed. São Paulo: Malheiros, 2004.

TAMIOZZO, Henrico César. A responsabilidade social empresarial e o direito ao trabalho humano decente: reflexos positivos para a empresa. In: SILVA, Wanise Cabral; MISAILIDIS, Mirta Gladys Lerena Manzo de; BARBATO, Maria Rosaria (org.). Anais do XXI Congresso Nacional do CONPEDI: O Novo Constitucionalismo Latino Americano: desafios da sustentabilidade. ISBN: 978-85-7840-125-2. Florianópolis: FUNJAB, 2012.

TRAMONTIN, Odair. Incentivos Públicos a Empresas Privadas e Guerra Fiscal. Curitiba: Juruá, 2002.

VERA, Leila Cristina Rojas Gavilan; LIMA, Edimilson de Souza. O meio ambiente do trabalho equilibrado e o desenvolvimento humano. In: GUNTHER, Luiz Eduardo (Coord.). Tutela dos Direitos da Personalidade na Atividade Empresarial. Curitiba: Juruá, 2010. 
VINHA, V. As empresas e o desenvolvimento sustentável: da eco-eficiência à responsabilidade social corporativa. In: MAY, P.H.; LUSTOSA, M. C.; VINHA, V. (Org.). Economia do Meio ambiente: teoria e prática. 6. ed. Rio de Janeiro: Elsevier, 2003.

WCED. Our Common Future. Oxford, Oxford University Press 